Proc. Indian Acad. Sci. (Earth Planet. Sei.), Vol, 90, No. 3, November 1981, pp. 245-262. C Printed in India.

\title{
Solar activity and Indian weather/climate
}

\author{
H N BHALME, R S REDDY, D A MOOLEY and \\ Bh V RAMANA MURTY \\ Indian Institute of Tropical Meteorology, Pune 411 005, India \\ MS received 6 October 1980 ; revised 27 July 1981
}

\begin{abstract}
The literature on influences of solar activity on the Indian weather and climate is reviewed since the discovery of sunspot cycle. Fluctuations in solar activity are undoubtedly a factor affecting weather and climate. Although the results of some of the studies are conflicting, Indian weather and climate is, in general, inversely related to sunspots. However, the areal extent of floods in India seems to expand and contract in phase with the Hale double sunspot cycle, suggesting that the flood rhythm is in some manner controlled by long-term solar activity related to solar magnetic effects. All the evidences of solar influences,on weather and climate may have practical implications in improving long-range forecasting of weather and climate, once the physical coupling mechanisms and their modification by other factors are clearly understood. Some of the promising plausible physical mechanisms for explaining solar effects on weather and climate are also discussed.
\end{abstract}

Keywords. Sunspot cycie ; Hale sunspot cycle ; sotar activity ; monsoon ; droughts ; floođs.

\section{Introduction}

The appearance and disappearance of sunspots were among the first observations made after the invention of the telescope in the early seventeenth century. Detailed studies in this regard with powerful telescope had to wait till the nineteenth century. Schwabe, a German astronomer, discovered that the number of spots visible on the Sun's surface rise and fall in a regular manner with a periodicity of about 11-years. His first announcement of this important result was given in the "Astronomische Nachrichten" in 1843. However, it was only in 1857 that this great discovery received universal acknowledgement and the Gold medal of the Royal Astronomical Society of England was awarded to Schwabe.

Solar activity is the collective name for all types of variation in the appearance or energy output of the Sun. The best known features of inconstant behaviour of the Sun are the sunspots. Sunspots are temporary dark regions on the surface of the Sun, associated with strong magnetic activity. They appear dark only because they have lower temperature than the surrounding photosphere. 
They remain visible from hours to months. The basic measure of solar activity is the number of sunspots visible on the surface of the Sun at any given time; the more the spots, the more active is the Sun. The only systematic indices available of the history of solar activity over any long period of past years relate to sunspots, Because of the wide fluctuations of the daily number of spots, the level of solar activity is generally expressed as monthly or annual mean values. The annual mean values of s'unspots show a very murked and persistent oscillation of approximately 11-year period with alternate maxima of high and moderate intensities. The ascent to maximum, which is over 3 to 4 years, is steeper than the decline. Sunspot numbers show an 11-year period but the true length of the cycle is 22 years, when the alternation of the sign of spot magnetic fields is considered. The leading spot in the northern hemisphere has a mignetic polurity opposite to that of the leader in the southern hemisphere, and the polarity of the leader reverses at the beginning of each 11-year cycle. Thus the m ignatic pariod of the Sun is twice the 11-year cycle, i.e. 22-year cycle which is known as the double sunspot cycle or Hale cycle after its investigator. On shorter time scale, there is the 27 -day period of the solar rotation. Sunspots move steadily across the face of the Sun. The motion is due to a rotation of the Sun about an axis. A remarkable feature of the Sun's rotation is that it does not rotate as a rigid body; the nearer the equator faster is the rotation. The synodic rotation (i.e. the rotation relative to the earth) period of the sunspots in different heliographic latitudes ranges between the extremes 24.4 and 31.2 days, the mean rotation period being $27 \cdot 2$ days.

Some more spectacular solar features are solar faculae and solar flares. The brighter irs is ir ond the sinspots are called faculae, in which solar output of radiation is intensified. The faculae fade away very much more slowly than the sunspots with which they are associated. The faculae may remain visible for up to a few months after the disappearance of a large sunspot group. An active Sun produces brilliant but transient solar flares. These are observed nenr sunspots, with a life cycle of a few minutes to a few hours. The flares are sources of intense burst of electro-mignatic enargy in the visible, ultra-violet and $\mathrm{x}$-ray portion of the spectrum. With large flares, the Sun often emits electrically charged particles, protons, electrons and alpha particles, sometimes referred to as solar cosmic rays. The frequency of all these features is similar to that of sunspots, and their 11-year variation is called the cycles of solar activity.

The possible relationship of sunspots with weather and climate has been a subject of study since long. Soon after the discovery of 11-year cycle in sunspots, the question was raised as to a possible relation between solar changes and terrestrial weather. Since then considerable amount of work has been done in many countries to discover ralationships between sunspot numbers on the one hand and the wather or the climite on the other, with the objective of long-range forecasting. The literature on the subject is very large but the question of the influence of sunspots on terrestrial weather and climate is still a matter of controversy due to the evidence being often localized, isolated and contradictory. An extensive and most critical survey of the evidence for quasiperiodicities of wather and climate around 11- and 22- year period has been made by Pittock (1978).

In the present 11-year sunspot cycle, the sunspot minimum was observed in 1976, and a new cycle began from August 1979. The period from 1 August 1979 to 
28 February 1981 is being observed as "Solar Maximum Year (SMY)". It seemed appropriate to survey, therefore, the literature on solar influences on Indian weather and climate.

We present here a review of literature on solar influences on Indian weather and climate since the discovery of the sunspot cycle, classified according to the subject matter. The plausible physical mechanisms for explaining solar effects on weather and climate are also discussed.

\section{Rainfall}

Early in 1877, Hunter (Blanford 1877), published a pamphlet entitled "The cycle of drought and famine in southern India", according to which the annual rainfall of Madras city in the period $1813-1876$ shows a regular cyclic variation in a period of about 11 years and there is a remarkable tendency to a deficiency in the rainfall at the epoch of sunspot minimun. He also stated that the severe famines and scarcities in the various parts of southern India tend to recur at intervals of about 11-years, at the epoch of sunspot minimum. Hunter deduced conclusions about the cyclic variation of rainfall of southern India, solely from the rainfall records of Madras city thus laying himself open to a good deal of criticism. It is difficult to accept that a deficiency in rainfall of Madras city indicates a deficiency productive of famines over a large area of southern India.

Blanford (1877) examined annual rainfall of seven stations situated in various parts of southern India from which it appears that there is no evident relation between rainfall and sunspots. However, by ingeniously combining the observations from the different stations, the amount of rainfall over southern India could be shown to vary on the average from iabout $5 \%$ over the mean, to $5 \%$ under the mean at different periods of the 11-year cycle. These periods do not, however, coincide exactly with the maximum and the minimum epochs of sunspots.

The possibility of forecasting future famines was under urgent discussion before the Indian Famine Commission in 1880. Pogson (1879), the then Government Astronomer in Madras, stated in a report to the Indian Famine Commission that there is an intimate connection between sunspot frequency, annual rainfall and grain prices in Madras. Pogson believed that the discovery of correlation with sunspot cycle could be useful in forecasting future famines. However, even today the intensive study of Indian monsoon failed to lead to an acceptable forecast of famine conditions.

Hill (1879) examined rainfall of north Indian stations. He was able to show that both summer and winter rainfall vary in an 11-year cycle, corresponding with that of sunspots, but in opposite directions. His tabulated data indicate that while excessive summer rains occur within two or three years following sunspot maximum, very deficient summer rains occur during sunspot minimum. The highest winter rainfall precedes the years of sunspot minimum, and the lowest coincides with the epoch of sunspot maximum.

The subject was extensively investigated by Walker (1915). He made worldwide survey of correlation coefficients connecting sunspot number with annual rainfall. (even though the main objective was improvement of the rainfall 
forecast over India). The correlation coefficients were, in general, 0 an $1 \pm 0.2$, and $w r e$ inconsistent and insignificant. Actually the prospects of finding useful coefficients were reduced by Walker ignoring in this instance all seasonal changes and working only with annual values. It is obvious that summer and winter rainfall must in some cases occur under entirely dissimilar conditions, and hence may have quite different relationships with solar activity.

There is a big time gap of four decades in research on the subject. Research in this field was, perhaps, dropped or discouraged because of the conclusion readily drawn that the solar variation had nothing to do with the changes of the worldwide circulation and rainfall distribution.

Sen Gupta (1957) found striking inverse relationship between sunspot cycle and days of excessive heavy precipitation over Tamil Nadu during the northeast monsoon in the period 1906-1955 (figure 1). The drought conditions often approached during sunspot maximum. This evidence conflicts' with the earlier work of $\mathrm{H}$ 'nter who stated that the severe famines and scarcities over this area occur at the epoch of sunspot minimum. The time span of data analysed differs in their studies. The relationships between sunspots and meteorological parameters often remain statistically significant for some periods after which they change sign or cease to exist at certain unpredictable times because of phase change in the relationship (Bell 1977). It is apparent that phase change in the relationship might have occurred in between the period of their studies. Deshpande (1968) analysed the January rainfall data in the plains of West UP adopting Sen Gupta's method and he also arrived at similar conclusions.

Koteswaram and Alvi (1969) examined the SW monsoon rainfall of west coast stations in India. They found that rainfall series at Trivandrum and Cochin are in opposite phase from 1910 to 1940 (figure 2). They also found long period

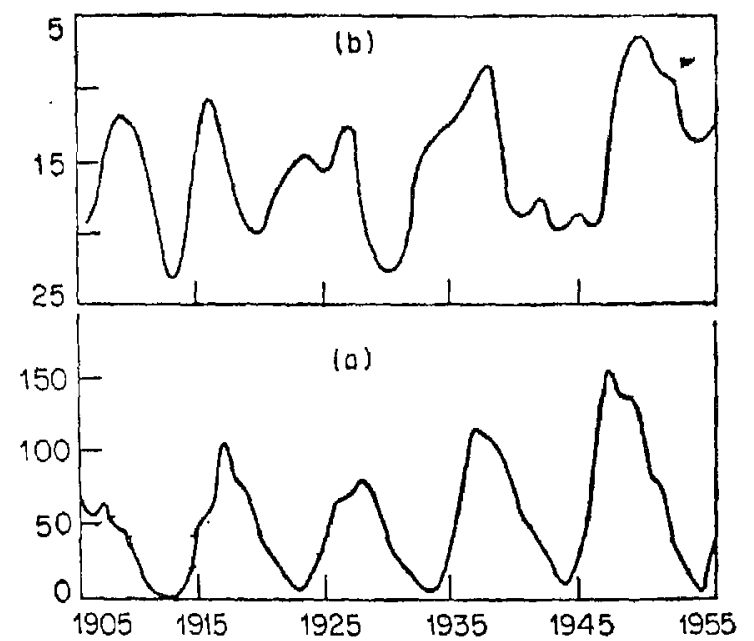

Figure 1. (a) Sunspot cycle. Ordinate: sunspot number (b) Variation of excess daily rainfall over Tamil Nadu State, Ordinate (reversed) : number of days with daily rainfall double the normal value or more (Sen Gupta 1957). 


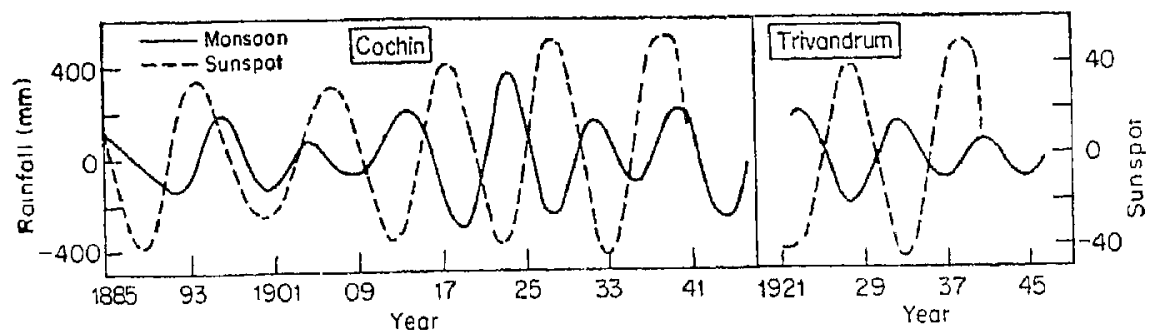

Figure 2. SW monsoon rainfall and sunspots (Koteswaram and Alvi 1969).

trends in rainfall at Bombay, Ratnagiri and Vengurla following the trend of sunspot numbers from the start of present century. Similar results have also been reported for common stations by Mukherjee and Singh (1978).

Jagannathan and Bhalme (1973) and Bhalme (1975a) have brought out the evidence that $\mathrm{SW}$ monsoon rainfall is influenced by sunspot activity. The authors analysed more than one hundred stations evenly distributed in India after brz.lking thə distribution of rainfall during SW monsoon into six seasonal orthogonal distribution parameters at each station. Power spectrum analysis of distribution parameters revealed significant periods corresponding to sunspot cycle with regional preferences. In the regions of orographic rainfall near the Himalayas, strong positive correlations are found, whereas in other regions there are negative correlations. Zones of positive and negative correlation are separated by areas of little correlation. The rainfall is larger during sunspot maximum than during sinspot minimum over sub-divisions close to the foot of the Himalaya. Over the rest of the country, rainfall is larger during sunspot minimum. The variations with sunspot cycle are dominant in the areas where rainfall is inffuenced by orography. The differences are up to $20 \%$ of the normal rainfall. They attributed the phenomenon to sunspot influence on circulation features which give rise to more storms and depressions and negative pressure anomalies across India about $2{ }^{\circ} \mathrm{N}$, near the time of sunspot minimum. Pittock (1978) criticized about the "eyeb illing" on the area which may profitably yield apparent 11-year cycle and quoted the paper by Bhalme (1975a), which analyzed data for Rajasthan. One should not expect sunspot cycle signal all over the vast country like India. There are the so called "soft spots" like semi-arid and arid climatic regions where 11-year or 22-year sunspot signal is found to be present in climatic data (Rao et al 1973; Bhalme 1975a; Mitchell et al 1979). This does not put any real relationship between sunspot and rainfall in doubt but warrants possible ex llination for spatial modulation of solar influence on rainfall.

Parthasarathy and Mooley (1978) correlated long series of SW monsoon rainfall for the whole of India with sunspot number as well as sunspot area index and found positive correlation close to the $5 \%$ significance level. Their result contradicts the finding of Jagannathan and Bhalme (1973) which shows SW monsoon rainfall to be negative correlated with sunspots over major parts of the country. Parthasarathy and Mooley (1978) considered SW monsoon rainfall for India as a whole. It is well-known that areas adjacent to the foot of the Himalaya and areas of rest of the country have opposite characteristics. During 
SW monsoon when there is heavy rainfall along and near the foot of the Himalaya there is a striking decrease in rainfall over most of the country. In such cases the combination of areas of opposite tendencies might mask important features and summation of rainfall for the whole of India would be misleading.

Chhabra et al (1978) examined annual rainf all over NW India and the Peninsula by the application of digital filters and spectral methods. They found 21-year cycle close to double sunspot cycle over the Peninsula ; but 32-year cycle over NW India in the filtered series. They have ignored seasonal changes in rainfall and worked with annual values. The SW monsoon accounts for almost entire annual rainfall in the Peninsular India but NW India receives significant rainfall both during SW monsoon season and winter season. An analysis of seasonal rainfall rather than annual values might have thrown further light on the difference in the behaviour of rainfall over NW India and Peninsular India.

The work reported on short-term oscillations of sunspot activity and rainfall is limited. The importance of short-term solar effects has been recognized only recently (Knight and Sturrock 1976 ; Reddy and Ramana Murty 1978). Reddy et al (1976) found significant inverse relationship between day-to-day variations of sunspots and NE monsoon rainfall over Tamil Nadu (figure 3). The inverse relationship is conspicuusly noticeable for the year 1964 and does not exhibit the same confidence for the year 1968. Power spectrum analysis of daily sunspots and rainfall during NE monsoon revealed significant 30-day and 15-day periodicity in sunspot activity and rainfall respectively (figure 4). They also found 30-day periodicity in daily sunspot activity and SW monsoon rainfall over Tamil Nadu (figure 5). Reddy et al (1980) further investigated coherency between sunspot activity and SW monsoon rainfall which showed a peak significant at $95 \%$ confidence level corresponding to 30 -day period with a phase lag of 1.8 days suggesting that sunspot activity and rainfall are interrelated during, SW monsoon.

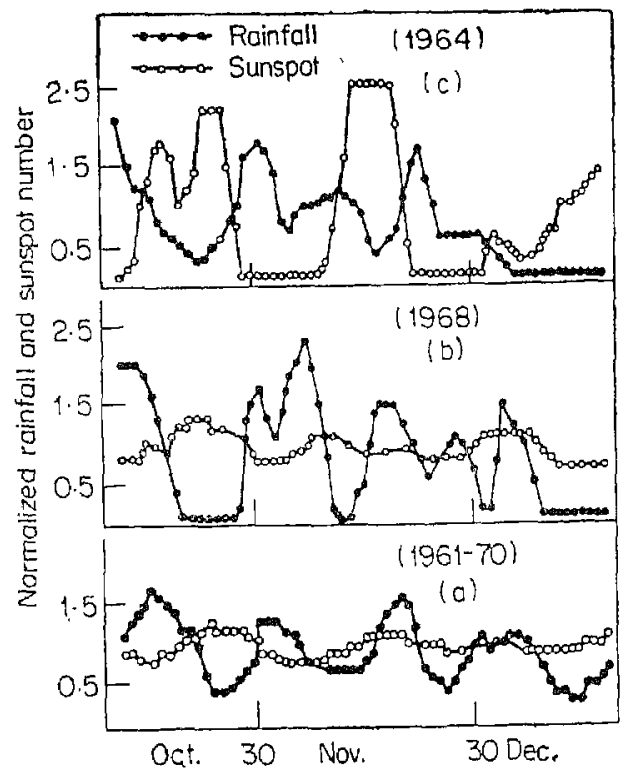

Figure 3. Sunspot and rainfall during NE monsoon over Tamil Nadu (Reddy et al 1976) 


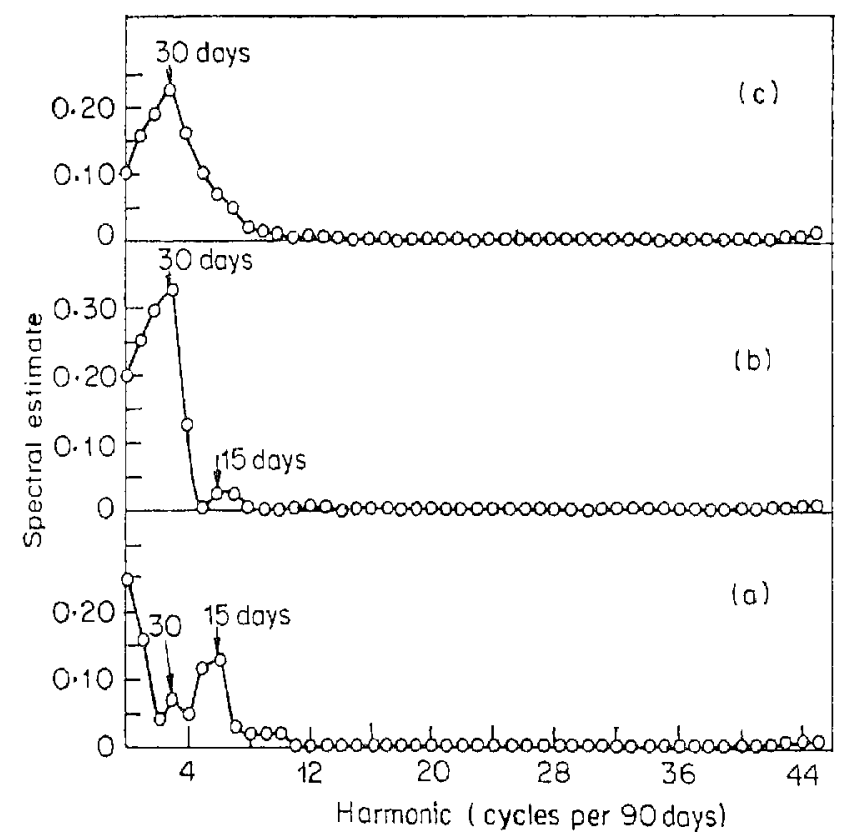

Figure 4. Power spectra of sunspots and rainfall during NE monsoon over Tamil Nadu, (a) rainfall, daily means over the period $1961-70$, (b) sunspots, daily means over the period 1961-70, (c) sunspots, daily means over the period 1889-1938 (Reddy et al 1976).

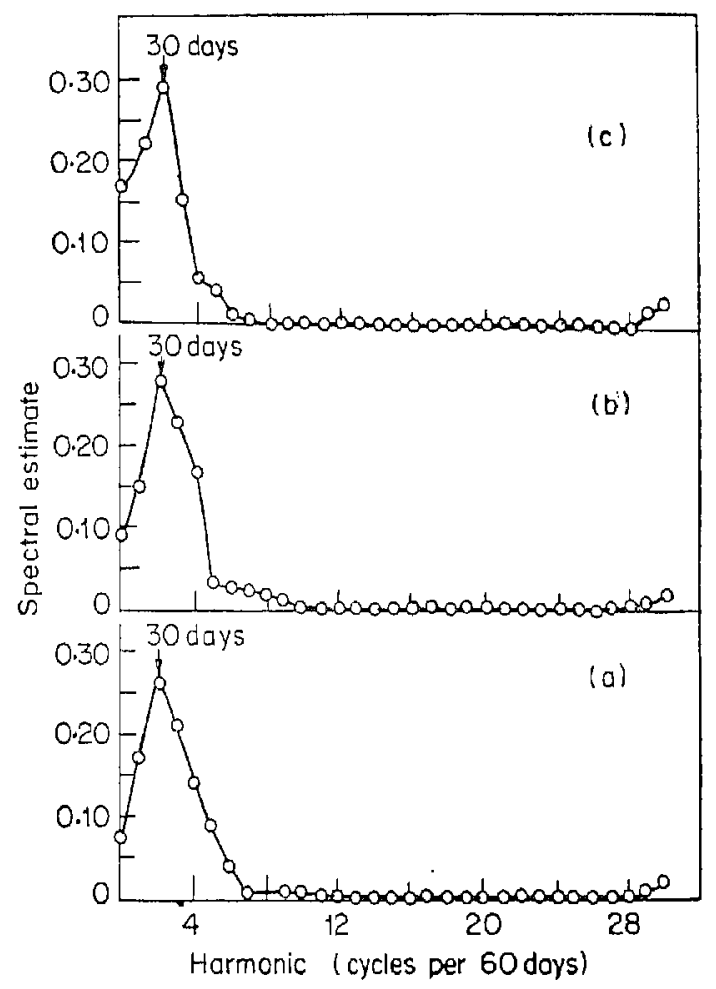

Figure 5. Power spectra of sunspots and rainfall during SW monsoon over Tamil Nadu, (a) rainfall, daily means over the period $1961-70$, (b) sunspots, daily means over the period 1961-70, (c) sunspots, daily means over the period 1889-1938 (Reddy et al 1978) 


\section{Temperature}

Dallas (1894) investigated annual temperature during the years 1858 to 1879 in equatorial sea area in the Bay of Bengal. He found that there exists a belowaverage temperature when the number of spots is low and vice versa. The evidence, however, is less satisfactory than that which connects rainfall and pressure with sunspots.

Walker (1915), however, found correlation between -0.2 and -0.5 on land stations of India, thus contradicting the observation made by Dallas. Accepting the view that at times of maximum sunspots the heat radiated by the sun tends to be at its maximum, it is natural to suppose that at such times we should find an increase in all consequences of the sun's radiation. Walker concludes by saying "Accordingly the marked fall in temperatures in tropical regions calls loudly for an explanation".

A study by Jagannathan (1963) of the mean annual temperature from stations of arid and semi-arid regions of India and from different continents shows lower temperature during sunspot maximum than during sunspot minimum at practically all stations.

Bhargava and Bansal (1970b) found a cycle nearer to sunspot cycle in monthly temperature data of non-coastal stations of the Peninsular India. But they have not examined whether or not monthly temperature is interrelated to sunspots by cross-spectrum analysis. They carried out such analysis in their earlier studies for 27-day period described below.

Bhargava and Bansal (1970a) carried out cross-spectral analysis on daily maximum temperature of Indian stations during 1946-47, a period when the sunspot activity underwent regular 27-day oscillations over a period of many solar rotations. They found exceedingly strong relationship between daily sunspot numbers and maximum temperatures over peninsular stations. The temperature changes followed the changes in sunspot numbers by an interval of 2 to 4 days. Cross-spectral analysis showed statistically significant coherence corresponding to 27-day period, suggesting that during high and recurrent solar activity a 27-day cyclic change in maximum temperature followed the sunspot activity in peninsular and equatorial region of India. However, such work is awaited on the periods of moderate, and low sunspot activity as well as for intervals when the sunspot activity is relatively more sporadic. A 27 -day variation of daily maximum temperatures in summer 1947 was also found by Visser (1958) in the Netherlands and in the USA. However, Visser's studies failed to disclose such cycles in other years.

\section{Pressure}

The variable that seemed to offer the best chance of providing a physical interpretation of the sun-weather interaction is the atmosphere pressure. Blanford (1880) showed that there were opposing oscillations in the pressure between IndoMalaysian area and Russia such that the pressure was at a maximum in the Indo-Malaysian area at the epoch of minimum sunspots, and in the Russian area at that of maximum sunspots. 
Dallas (1894) investigated the pressure in equatorial sea area of Bay of Bengal, and found a fairly clear cyclic variation in the pressure over the years 1858-1879. But the pressure and sunspot curves are not synchronous nor is there any apparent relation between the phases of the two variables. Although the two curves are not synchronous, it is apparent from the curves that there exists a striking agreement between them. The gradual fall from the maximum to the minimum and the sudden rise from minimum to maximum, which is so typical of the sunspot curve, occur almost equally strongly in the pressure curve of the same period, and it is hardly possible to suppose that this general agreement can be merely fortuitous.

Walker (1915), from the world-wide survey of correlation coefficients connecting sunspot number with annual mean surface pressure has pointed out that the contrast between the zones of low and high pressure is apparently controlled to some extent by variation of sunspots. The correlation coefficients with 40 years of data ranged up to -0.30 to -0.40 over India, Ceylon, South Australia and up to +0.20 to +0.35 over Green Land, southern USA, across Russia and South America. There was a suggestion that when sunspots become more numerous, pressure increases in the areas where it is already high and decreases in those where it is already low.

Jagannathan and Bhalme (1973) have shown that the sumspot influence on SW monsoon rainfall is spatially modulated resulting in systematic variations of the sign and degree of corralaion. They attributed the phenomena to sunspot influence on circuiation features. They demonstrated this by compositing surface pressure anomalies charts and storm tracks during maximum and minimum sunspot epochs. During sunspot maximum the core of the negative pressure departures lies near the foot of the Himalaya, as in the case of monsoon break and causes greater rainfall in adjoining areas (figure 6). The total number of days of break in the monsoon is significantly larger during sunspot maximum than during sunspot minimum. During sunspot minimum epoch monsoon trough is more marked and situated farther south as in the case of active monsoon condition.

Bell (1977) calculated correlation coefficients over sliding 15-year intervals between annual sunspot number and intensities of SW and NE monsoons (defined by pressure difference). He found fluctuations ranging from +0.5 to -0.5 over

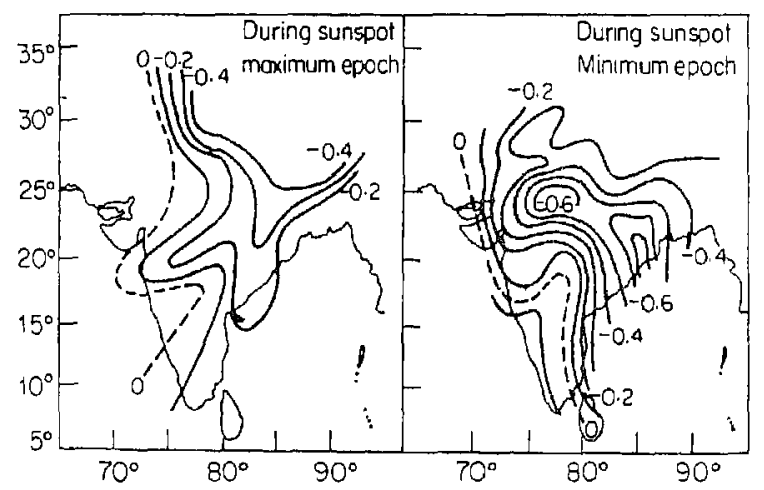

Figure 6. Surface pressure departure (nb) during monsoon season (Jagannathan and Bhalme 1973). 


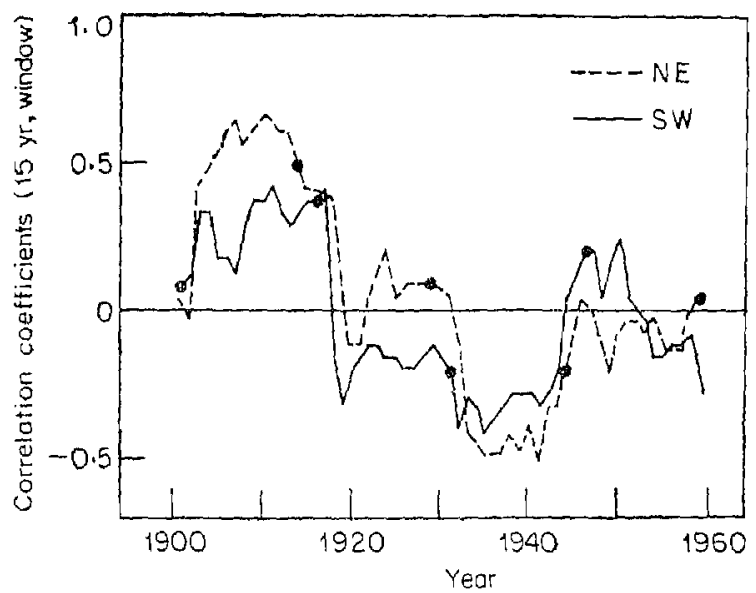

Figure 7. The variation of the correlation coefficient between mean annual sunspot number and (1) the intensity of the $N E$ monsoon (NE) as given by the mean pressure difference in January between Irkutsk and Tokyo, and (2) intensity of the SW monsoon (SW) as given by the mean pressure difference in August between Cuttack and Trivandrum. In each case the correlation coefficient is for 15 years and is plotted against the cate of the first year. The dots are independent correlation coefficients for 15 years. The SW curve has been inverted (Bell 1977).

different invervals (figura 7). The intensities of both the SW and NE monsoons apparently respond to solar influences associated with sunspots for a few years at a time but show phase changes commonly around 1920 and 1940. At the peak of both phases the responses of the SW and NE monsoons tend to be of opposite sign, the one being intense when the other is weak.

\section{Storms/depressions}

Raghavan (1961) found that the number of monsoon storms/depressions striking the Bay coast near Calcutta respond to annual sunspots. He showed inverse relationships between them. Upper winds at $4 \mathrm{~km}$ and above indicated that the decline of storms/depressions striking the coast is accompanied by a southward shift of the Tibetan summer anti-cyclone in the years of maximum sunspot activity.

Jaganzathan and Bhalme (1973) found smaller frequency of storms/depression: and shorter westward extent of their tracks during sunspot maximum than durins sunspot minimum (figure 8). Bhalme (1975b) also reported statistically signif cant (at $5 \%$ level) inverse relationships between the number of monsoon storms depressions and annual sunspots, and an apparent cycle with a period o about 40 years superimposed on linear decreasing trend in monsoon storm depressions and annual sunspots, and an apparent cycle with a period of abor 40 years superimposed on linear decreasing trend in monsoon storms/depressior also showing inverse resemblance with sunspot trend in recent years (figure 9). 

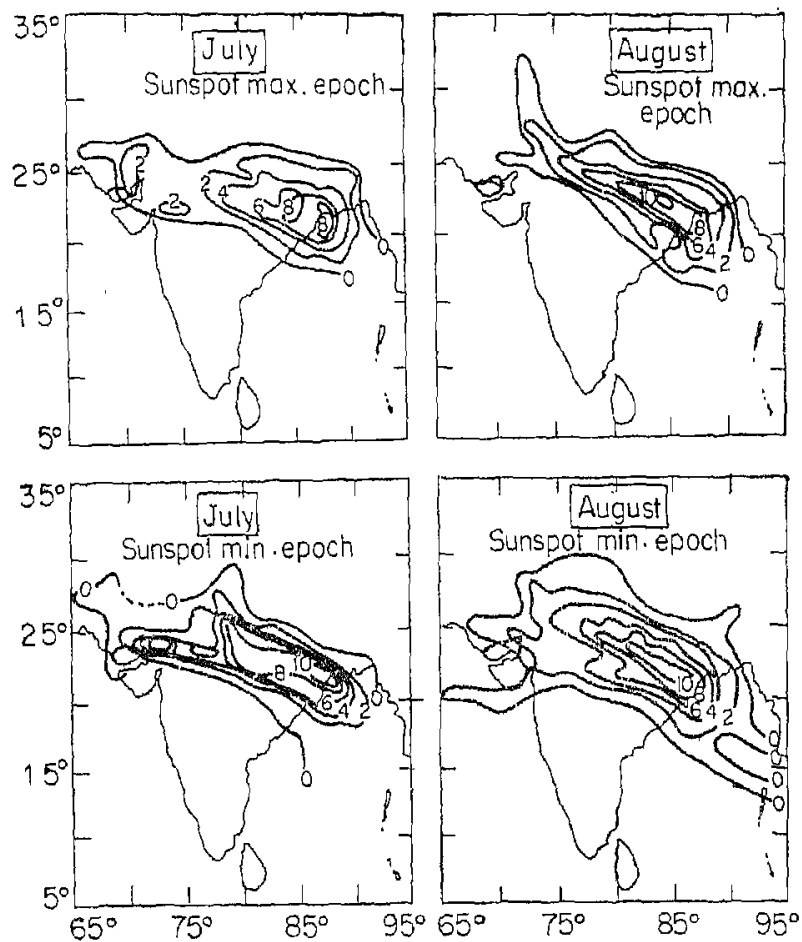

Figure 8. Frequency of storms and depressions (Jagannathan and Bhalme 1973).

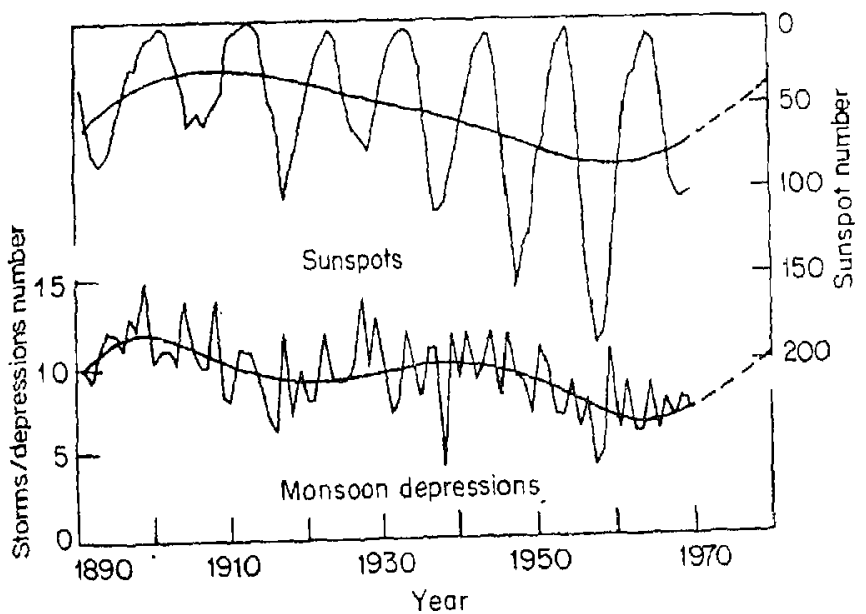

Figure 9. Trends in monsoon storms/depressions and sunspot numbers (Bhalme 1975b).

\section{Tropopause}

Rajaram et al (1979) correlated annual menn tropopause height of 11 Indian stations with sunspot number in the period 1960-72 which include minimum and maximum of the ll-year sunspot cycle. They found correlation coefficient to be 
latitude-dependent. Significant simultaneous negative correlations are observed for the stations above $18^{\circ} \mathrm{N}$. The correlations are not significant south of this latitude.

\section{Other climatic parameters}

Rao et al (1973) worked out Palmer drought indices for different meteorological sub divisions of India. Power spectrum analysis of the drought indices showed significant periodicity close to sunspot cycle over West Rajasthan.

Bhalme and Mooley (1979) found that Palmer drought index fails to describe realistic drought intensity in a tropical country such as India where rainfall is highly concentrated in a season. Palmer index has been modified by them to suit the weather conditions in India. The modified drought index is observed to produce better and realistic results. Power spectrum analysis of seasonal modified drought indices revealed a significant period close to sunspot cycle over semi-arid and arid areas of northwest India. A student $t$-test was applied to the data of \% number of events of severe or worse drought relative to the year from sunspot maximum. The analysis confirms that there is a statistically significant (better than $1 \%$ level) tendency of severe or worse drought to occur in the years following the sunspot maximum (figures 10 and 11).

Kane and Dhanju (1978) examined periodicities in annual river discharges of Indian rivers by maximum entropy spectral analysis. They reported spectral peak near double sunspot cycle in Godavari discharge values.

Bhalme and Mooley (1980) developed an index of drought/flood based on monthly monsoon rainfall and duration. Drought Area Index (DAI) is defined by them as the percentage area of India in a year having monsoon index $\leqslant-2$, i.e. moderate or worse drought severity and likewise Flood Area Index (FAI) is the percentage

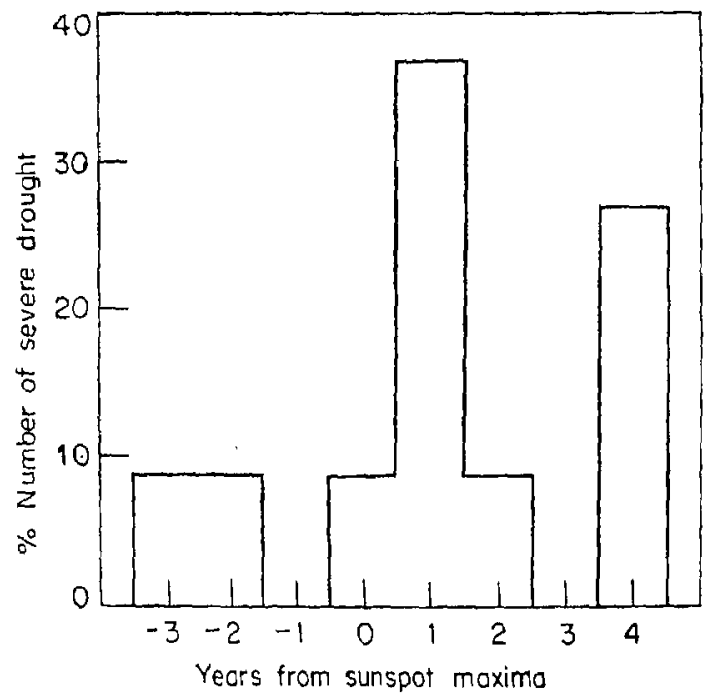

Figure 10. Distribution of severe or worse drought years over Jaipur district, relative to sunspot maximum (Bhalme and Mooley 1979). 


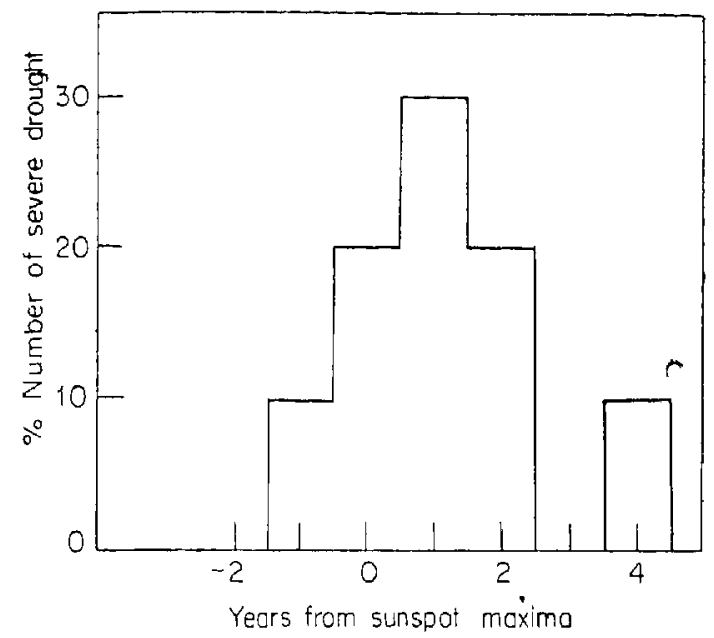

Figure 11. Distribution of severe or worse drought years over Jodhpur district, relative to sunspot maximum (Bhalme and Mooley 1979).

area of India in a year with monsoon index $\geqslant+2$, i.e. with moderate or more wet conditions. Power spectrum analysis revealed a weak triennial cycle in DAI series and highly significant cycle of 20 year, near a double sunspot cycle (it has averaged 21-year during the period under study) in FAl series. Figure 12 displays the years of high amplitude sunspot maxinum $\left(X_{\mathrm{h}}\right)$, the years of low anplitude sunspot maximum $\left(x_{1}\right)$ and a wave of 21-year in sunspots and in FAI series. The FAI series s in phase with the double sunspot cycle and large-scale flood events over India occurred remarkably in the high amplitude maximum phase of sunspot cycle. Note the absence of large-scale floods in the low amplitude sunspot cycle. The most recent work by Bhalme and Mooley (1981) provides a convincing evidence of $\sim 22$-year cycle in the fluctuations of the flood area over India and various statistical tests have demonstrated a strong coherence with the double (Hale) sunspot cycle suggesting a real connection. The feature suggested is in conflict with the finding by Jagannathan and Bhalme (1973). The present results of the studies by Bhalme and Mooley (1980) suggest that the weather associated with high amplitude and low amplitude sunspot cycle has opposite characteristics. Perhaps Jagannathan and Bhalme (1973) would have got more impressive results had they considered differences in high amplitude and low amplitude sunspot cycle which have opposite polarity. Mitchell et al (1979) also found highly significant rhythm of double sunspot cycle in the drought area over the US Central Great Plains. The large-scale drought occurred within two or three years following low amplitude sunspot maximum. The association between drought area changes and double sunspot cycle has been established by them with sufficient confidence. The evidence of double sunspot cycle in Flood Area Index over India and in the drought area changes over the US Central Great Plains is suggestive of inverse behaviour of weather in double sunspot cycle mode. It however, needs further study to explore the possibility of climatic prediction from the inverse behaviour of weather as indicated above and possible causal mechanism. 

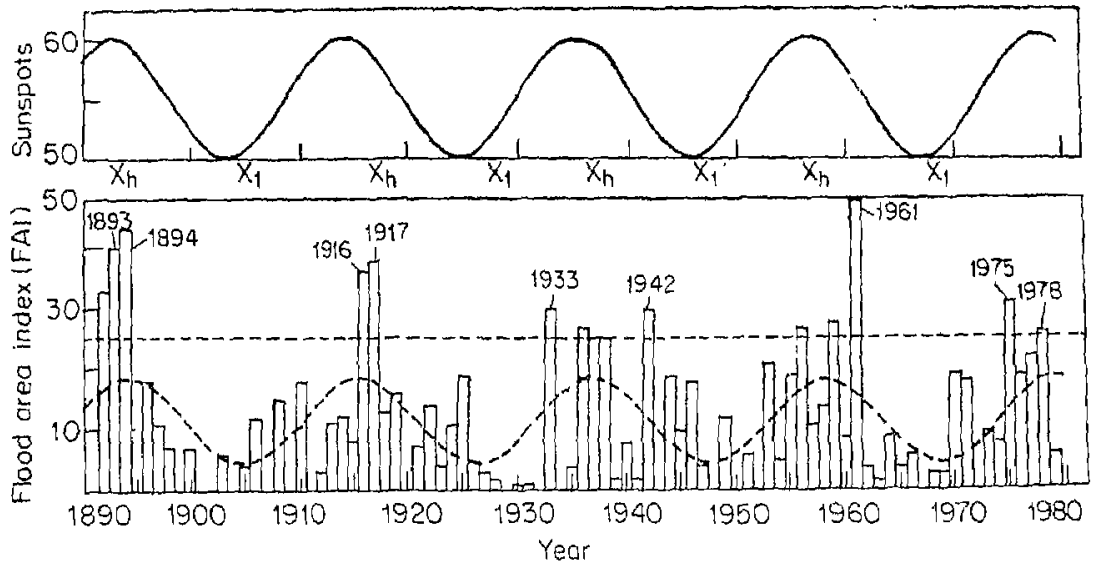

Figure 12. Lower: Flood Area Index (FAI), the years of high amplitude sunspot maximum $\left(X_{h}\right)$, the years of low amplitude sunspot maximum $\left(X_{1}\right)$, and a wave of 21-year period in FAI series. Upper : A wave of 21 year period in mean annual sunspot number (Bhalme and Mooley 1980).

\section{Mechanisms}

In the foregoing sections we reviewed evidence for significant relationslips between solar activity and meteorological phenomena on different time scales. The fundamental scientific question centres on what physical processes or causeeffect mechanisms might act to couple the variable solar energy with the atmospheric system and produce the observed relationships. A number of possible coupling mechanisms have been suggested but widely accepted physical mechanism has not yet emerged. We present some of the plausible mechanisms which merit attention.

\subsection{Variations in solar constant}

The sun is the prime source of energy for all atmospheric processes. It is natural to give frst consideration to changes in the incoming solar radiation received by the earth. Earlier work suggested that the solar constant, i.e. the electromagnetic radiation from the sun at the top of the atmosphere is not really constant, Allen (1958) considered that the solar constant could be regarded as constant. Only the ultra-violet part of the solar spectrum has large variations to the extent of about $10 \%$ on this wave length, varying in the phase with the 11-year sunspot cycle. Observations of the sun from satellite and rocket platforms have provided evidence that solar radiation varies noticeably in the ultra-violet portion of the spectrum over a solar rotation period of 27 days (Pollack et al 1979).

Sawyer (1963) has produced a convincing quantitative study showing that a $1 \%$ rise in the solar constant would probably lead to a rise in equatorial temperature of $1 / 2^{\circ} \mathrm{C}$ and a greater rise of $1^{\circ} \mathrm{C}$ in the high latitudes, which in turn can result in a decrease in the zonal circulation. Mitchell (1975) suggested that a small change in the solar constant would be sufficient to cause profound climatological change through direct heating effect at the Earth surface 
and the base of the atmosphere. Volland (1979) has shown theoretically that a $0.1 \%$ change in the solar constant with a solar rotation period of 27-days can generate tropospheric planetary waves with detectable magnitude. Volland's theoretical argument satisfactorily explains the important results of King et al (1977).

This mechanism did not receive widespread acceptance because it was argued that the solar constant is actually almost constant. The direct measurement of solar constant over the solar cycle from satellites show small variations of less than 1\% (Smith and Gottlieb 1975; Livingston 1979).

\subsection{Changes in ozolle concentration}

The ozone formed from oxygen molecules and free oxygen atoms in the stratosphere near the $50 \mathrm{~km}$ level absorbs the entire energy of the sun's radiation at wave lengths less than 0.3 micron. The total amount of ozone present in the atmosphere and its effect on temperature in stratosphere must vary with any variation in the amount of energy received from the sun at short iwave end of the solar spectrum. Though the total intensity of the solar beam appears nearly constant, the intensity of wave lengths that affect ozone production and decay does vary by large percentage in association with sunspots and solar flares. Heath and Thekaekara (1977) reported changes in the solar ultra-violet irradiance of $1 \%$ over a 27 -day solar rotation and about $10-20 \%$ over an 11-year cycle. On an 11-year, ozone production by solar ultra-violet radiation should be greater in sunspot maximum years. This is so far the only physical process certainly known by which solar activity affects the Earth's atmosphere below the ionosphere.

Another idea proposed by Ruderman and Chamberlain (1975) is that a solar cycle modulated cosmic rays can reach a meteorologically imporiant level of about 20-30 km. It could excite nitrogen leading to the formation of nitric oxide which in turn could deplete ozone in the stratosphere. It is well-known that there is an inverse relationship between intensity of cosmic ray and 11-year sunspot cycle. The loss of ozone by cosmic ray produced nitric oxide should be least at sunspot maximum and greatest at the sunspot minimum. Thus the ozone amount should be greatest with maximum production and minimum loss occurring during sunspot maximum. The total ozone amount of the atmosphere varies in phase with sunspot cycle (Willett 1962; Angell and Korshover 1973). Bates (1977) suggested a dynamical mechanism by which variations in solat ultra-violet radiation or changes in the ozone content of the upper atmosphere could lead to climatic change.

\subsection{Atmospheric electricity and thunderstorms}

The most promising and a much better scientific foundation mechanism for linking solar activity and weather has recently been suggested by Markson (1978). This mechanism does not critically depend on change in solar constant. He suggested that solar variability affects the current flow from thunderstorms and thus modulates the earth's electric field which may ultimately influence cloud physical processes, and this increased electric field may accentuate thunderstorms.

The question of whether increased thunderstorm activity is the cause or the result of an increased potential gradient remains open. However, the electrical part of the proposed machanism can be verified by experiments and analysis. 


\section{Concluding remarks}

(i) The results of some of the studies are conflicting because of ignoring seasonal changes, spatial differences, data over different periods and characteristics of sunspot cycle. In summary, it appears that :

(a) Rainfall. Indian SW/NE monsoon is, in general, inversely related to sunspot activity. During the SW monsoon, 30-day periodicity is observed in the daily sunspot activity and regional rainfall which are significantly interrelated (Reddy et al 1980). The NE monsoon rainfall is inversely related to sunspot cycle (Sen Gupta 1957). The SW monsoon rainfall exhibits a dependence on the 11-year sunspot cycle with regional preferences. Sunspot influence on rainfall is spatially modulated in unknown ways, resulting in systematic variation of sign and degree of correlation (Jagannathan and Bhalme 1973).

(b) Temperature. There is a strong positive correlation between daily sunspots and maximum temperature, and a 27-day cyclic change in daily maximum temperature follows the sunspot activity in peninsular and equatorial regions of India (Bhargava and Bansal 1970). However, there is a negative correlation between sunspots and annual mean temperature, calling for an explanation.

(c) Surface pressure. There is a negative correlation between sunspots and annual surface pressure over the Indian region.

(d) Monsoon depressions. The number of monsoon storms/depressions and annual sunspots are inversely correlated (Bhalme 1975b).

(e) Flood areas. The most recent work by Bhalme and Mooley (1980, 1981) provides convincing evidence of $\sim 22$-year cycle in the fluctuations of an objectively defined flood area over India, expanding and contracting in phase with the double (Hale) sunspot cycle and furthermore largescale flood events occurred remarkably in the high amplitude maximum phase of sunspot cycle. Various statistcial tests have demonstrated a strong coherence between the flood area and the double (Hale) sunspot cycle, suggesting that flood rhythm is in some manner controlled by long-term solar variability directly or indirectly related to solar magnetic effects. It is worthwhile to give this aspect serious consideration in future research in the field.

(ii) It is very important to take account of the seasonal changes and solar cycle differences in any investigation of solar-weather relationships, otherwise analysis might produce misleading results.

(iii) Fluctuations in solar activity are undoubtedly a factor affecting weather or climate. Their relationships have already been established with sufficient confidence to justify an inquiry into the physical mechanisms (King 1975; Roberts 1975, 1979 ; Wilcox 1975 ; Mitchell et al 1979 ; Bhalme and Mooley 1981). 
(iv) The statistically significant and reliable evidences of solar-influences on weather and climate may have practical implications in improving long-range forecasting of weather and climate once the physical coupling mechanisms and their modification by other factors are clearly understood.

(v) Although several studies have been made on solar-weather relationships, it remains to be established how energetically small variations in solar output could produce energetically large dynamical responses at lower levels of the terrestrial atmosphere. It is hoped that the current solar maximum year programme may help to remove some of the obscurities that have surrounded the problem so far.

\section{References}

Allen C W 1958 J. R. Met. Soc. 84307

Angell J K and Korshover J 1973 Mon. Wea. Rev. 101426

Bates J R 1977 Q. J. R. Met. Soc. 103397

Bell G J 1977 Weather 3226

Bhalme H N 1975a Indian J. Met. Hydrol. Geophys, 2655

Bhalme H N 1975b Vayu Mandal 512

Bhalme $\mathrm{H}$ N and Mooley D A 1979 Hydrological aspects of droughts

Proc. of Symposium Dec. 3-7, 1979 Indian Inscitute of Technology New Delhi 373

Bhalme H N and Mooley D A 1980 Mon. Wea. Rev. 1081197

Bhalme $H \mathrm{~N}$ and Mooley D A 1981 J. Appl. Met. 201041

Bhargava B N and Bansal R K 1970a Indian J. Met. Geophys. 21285

Bhargava B N and Bansal R K. 1970b Indian J. Met. Geophys. 21355

Blanford H F 1877 Report of the Indian Famine Commission 1880, Miscellaneous, 27

Blanford H F 1880 Nature (London) 20479

Chhabra B M, Arora B R and Raipal D K 1978 Proc. of symposium on hydrology of rivers with small and medium catchnents, April 17-19, 1978 New Delhi 2-15

Dallas W L 1894 India Met. Memoirs 61

Deshpande D V 1968 Weather 2378

Heath D F and Thekaekara M P 1977 The solor output and its variation (ed,) O R White (Colorado Associaied University Press, Boulder) 193

Hill S.A 1879 Indian Meteor. Mem. 1183

Jagannathan_P 1963 Indian J. Met. Geophys. 143

Jagannathan P and Bhalme H N 1973 Mon. Wea. Re\%. 101691

Kane R P and Dhanju N S 1978 Irrig. Power 35221

King IW 1475 Aeronaut Astronaut. 1310

King J W, Slater A J, Stevens A D, Smith P A and Wills D M 1977 J. Atmos. Terr. Phys. 391357

Knight JW and Sturrock P A 1976 Nature (London) 264239

Koteswaram P and Alvi S M A 1969 Curr. Sci. 38229

Livingston W C 1979 Proc. of Symp. Workshop on solar-terrestrial influences on weather and climate. Ohio State University, Ohio Aug 24-28, 1978

Markson R 1978 Nature (London) 273103

Mitchell J M Jr 1975 Gal'p. Publ. 16 WMO 127

Mitchell J M Jr Stockton C W and Meko D M 1979 Proc. of Symp./Workshop on SolarTerrestrial influences on weather and climate, Ohio State University, Ohio, Aug 24-28, 125 (1978)

Mukherjee A K and Singh B P 1978 Indian J Met. Hydrol Geophys. 29441

Parthasarathy B and Mooley D A 1978 Mon. Wea. Rer. 106771

Pittock A B 1978 Rev. Geophys. Space Plys. 16400

Pogson N R 1879 Report of the Indian Famine Commission 1880 Miscellaneous 31 
Pollack J B, Borucki W J and Toon O B 1979. Nature (London) 282, 600

Ragluavan K 1961 Weather $\mathbf{1 6} 59$

Rajaram M, Singh B P and Gupta H V 1979 Tellts 31515

Rao K N, George C J, Moray P E and Mehta N K 1973 Indian J Meteor. Geophys 24257

Reddy R S, Mukherjee B K and Ramana Murty Bh V 1976 Indian J. Radio Space Phys. 5298

Reddy R S, Parasnis S S and Ramana Murty Bh V 1980 Advances in Space Exploration, COSPAR Symp. Series, (Oxford U K ; Pergamon Press) 8237

Reddy R S and Ramana Murty BhV 1978 Indian J. Radio Space Phys. 7215

Roberts W 01975 Proc. of Symp. on possible relationships between solar activity and meteorological phenomena, Greenbelt, Maryland, Nov. 7-8, 1973 (eds) W R Bandeen and S P Maran NASA Report SP. 366, 13

Roberts W O 1979 Proc. of Symp./Workshop on Solar-Terrestrial influence on weather and climate, Ohio, State University, Ohio, Aug. 24-28, 1978, 29

Ruderman M A and Chemberlain J W 1975 Space Sci. 23247

Sawyery J S 1963 Proc. Rrme Symposium on changes of climate UNESCO 333

Sen Gupta P K 1957 Weather 12322

Smith E V P and Gottlieb D M 1975 Symp. on possible relation between solat activity and meteorological phenomena, Greenbelt, Maryland, Nov. 7-8, 1973 (eds) W R Bandeen and S P Maran NASA Report SP-366, 97

Visser S W 1958 Trans. Am. Geophys. Union 39835

Volland H 1979 Proc. of Symp. Workshop on Solar-Terrestrial influences on weather and climate. Ohio State University, Ohio, Aug. 24-28, 1978

Walker G T $1915 \mathrm{Mem}$. Indian Meteor. Dept. 21 17,61,91

Willett H C 1962 J. Geophys. Res. 67661

Wilcox J M 1975 J Atmos. Terr. Phys. 37237 